\title{
Effect of the Different Ski Length on the Level of Anxiety at Novice Skiers
}

\author{
Jan Jurečka \\ Masaryk University, Faculty of Sports Studies
}

\begin{abstract}
Efficient teaching of alpine skiing at the beginning of the teaching process should be the main goal of every ski instructor. In our research, we investigated the influence of different ski length on the efficiency of the alpine skiing teaching process, as well as on the level of state anxiety during alpine skiing of ski novices. The research was conducted on 34 participants (19 men, 15 women). The experimental group had skis of $130 \mathrm{~cm}$ in length with a $7 \mathrm{~m}$ radius from the brand Lusti. These skis are specialized for very short and aggressive turning including fun carving. The mean height of the participants from the experimental group was $178.07 \mathrm{~cm}( \pm 10.89)$. The control group had skis of the standard length according to the person's height. The mean height of the participants from the control group was $177.33 \mathrm{~cm}$ ( \pm 6.87$)$. The mean length of the skis was $158.6 \mathrm{~cm}$ with a 1.,05m radius. For our research, the following data were collected: pre-test, continuous test and post-test state and trait anxiety. In this paper, the main intention was to determine the effect of different ski length on the state anxiety level of novice skiers. The data were acquired from the questionnaire STAl, which shows the level of anxiety (Künzell, S. \& Müler, J., 2008; Koca, 2015). Based on the results we can say that teaching alpine skiing with the usage of short skis might be less stressful for novice skiers than with the usage of standard length skis.
\end{abstract}

Keywords: state-trait anxiety inventory, anxiety level, alpine skiing, education, short ski, snowplough, novice skiers

\section{INTRODUCTION}

The efficient teaching of alpine skiing at the beginning of the teaching process should be the main goal of every ski instructor. The efficiency of ski tuition is a frequently discussed topic all over the world. In their research Cigrovski et al. (2010) investigated whether novice skiers can accelerate their process of learning alpine skiing by omitting one of the basic elements of the alpine skiing methodological procedure - the snowplough. Their results show that omitting the snow plough is not an efficient way to teach alpine skiing. Similar research was also done by Joksimović et al. (2012). They also concluded that the snow plough is an important element for skiers to be able to learn the new and mainly advanced elements of alpine skiing.

On the other hand, there are ski instructors and scientists, who claim the exact opposite. One of the leading personality who promotes the so-called direct method is Ken Lawer. In 1996 he wrote a methodical guide for ski instructors where he described a direct method to learn parallel skiing with the omission of the snowplough. Besides omitting the snowplough he also suggested the use of shorter skis. Král (2012) conducted research, where he applied this method. The results demonstrated that short skis without the snowplough were superior to classic skis and the snowplough.

Another study with a similar goal was conducted by Künzell, S. \& Müler, J. (2008). They studied the level of anxiety during the learning process of novice skiers and how the anxiety was affected by the length of the skis. In their study, they compared the state anxiety of novice 
skiers using either standard skis with a length according to their height or short skis - so-called Bigfoots. The novice skiers with Bigfoots had a lower level of state anxiety than novice skiers using standard skis. Similar research led by Koca (2015) also focused on state anxiety during alpine skiing. He did not discover a significant difference in anxiety levels in ski novices either before or after a ski course.

In our research, we investigated the influence of different ski length on the efficiency of the alpine skiing teaching process, as well as on the level of state anxiety during the alpine skiing of ski novices. In this paper, we present the results from our measurements of state anxiety.

\section{METHODS}

\section{Subjects}

The research was conducted on 34 participants (19 men, 15 women). The mean age of the participants was $21.67 \pm 3.94$ years. All participants were novice skiers with no or minimal alpine skiing experience. The participants were intentionally divided into two homogenous groups. The distribution was based on the results from a general questionnaire, results from the Iowa Brace test and results from the State-Trait Anxiety Inventory (STAI) questionnaire. In the general questionnaire, there were questions regarding the current level of experience with skiing, inline skating (Božić et al., 2017; Roman et al., 2007; Takahashi, M. \& Yoneyama, T., 2001), ice skating and cross - country skiing. The Iowa - Brace test is usually used to determine motor skills as well as coordination (Havel, Z., \& Kynštová, H., 2013; Vobr, R., \& Heřmánek, R., 2018). To determine trait anxiety we used the standardized questionnaire STAI. In particular the STAI - X2 which is focused on the general level of anxiety. Based on the results from the STAI - X2 we were able to divide the participants into two homogenous groups with similar levels of trait anxiety.

The experimental group had skis of $130 \mathrm{~cm}$ length and a $7 \mathrm{~m}$ radius from the brand Lusti. These skis are specialized for very short and aggressive turning including fun carving. The experimental group consisted of 16 participants ( 8 men, 8 women). The mean height of the participants from the experimental group was $178.07 \mathrm{~cm}( \pm 10,89)$. The control group had skis of the standard length according to a person's height. The mean length of the skis was $158.6 \mathrm{~cm}$ with a $14.05 \mathrm{~m}$ radius. The control group consisted of 18 participants ( $11 \mathrm{men}, 7$ women). The mean height of the participants from the control group was $177.33 \mathrm{~cm}( \pm 6.87)$.

\section{Research procedure}

The teaching process was carried out according to the methodological manual for alpine skiing called Snowsport Manual - Blue Book for Alpine Skiing (Mical et al., 2017) which was developed in cooperation with the Association of Professional Ski Instructors (APUL). APUL is the leading organization in the Czech Republic in the field of ski instructor education. As mentioned in the introduction, there is not one united approach to alpine skiing education for novice skiers. In general, we can choose the classic approach which includes the snow plough element (Cigrovski et al., 2010; Joksimović et al. 2012; Mical et al., 2017) or the direct method, which omits the snow plough element. Omitting the snow plough is usually followed by the usage of smaller skis (Lawler, 1996; Král, 2012; Künzell, S. \& Müler, J.,2008). While the snow plough is considered to be a useful tool for learning the basic and advanced ski elements (Cigrovski et al., 2010) we decided to combine those two approaches. We used short skis in the experimental group while preserving the classical approach which includes the snow plough element.

In total four ski courses took place during our experiment. 9 participants attended the first and second courses and 8 participants who attended the third and fourth courses. Each course 
had the same ski instructor and similar conditions for skiing including the quality of the snow, weather, slope maintenance etc. All courses took place at the Piancavallo ski resort in Italy. Each course consisted of four days of training and one day of demonstration of the four ski elements (snowplough turn, wedge turn, parallel turn and carving turn). All participants had the skis with the standard length for the first 90 minutes of training on the first day. After 90 minutes the experimental group was given short skis. From that moment till the end of the third day of training, the experimental group trained on short skis. The teaching program was the same for both the experimental and the control groups in each course. At the beginning of the fourth day, the experimental group were given back their standard length skis. They had one day to transfer skills from short skis to standard skis. On the last and fifth day of the course, the participants demonstrated the four elements of alpine skiing.

\section{Data Collection}

For this paper, the data was acquired from the STAI questionnaire, which shows the level of anxiety (Künzell, S. \& Müler, J., 2008; Koca, 2015). From the STAI we can get information about the general level of trait anxiety (STAI - X2 form) or the level of actual state anxiety (STAI $\mathrm{X} 1$ form). In the questionnaires, participants use the Likert scale from 1 to 4 . Each form of the questionnaire consists of 20 questions and the final score is from $20-80$ points. The higher the score is, the higher the level of anxiety is. Participants completed the STAI - X2 questionnaire form before the course. Based on the results from the STAI - X2 we could divide the participants into two homogenous groups with a similar level of general trait anxiety. At the end of the second day of the course, participants completed the STAI - X1 questionnaire, which gives information about actual state anxiety. By that time, the experimental group had spent one and a half days on short skis. The same questionnaire was completed at the end of the fourth day of the course. The fourth day was also the first day when the experimental group had their standard length skis returned to them.

\section{Statistical Analysis}

The results were processed in the software Statistica 13.2. Based on the Shapiro - Wilk test the data had a normal distribution. We used a parametric t-test to find out if there was a statistically significant difference between the results of each group. We also determined the effect size by calculating the Cohen d.

\section{RESULTS}

The mean result from the STAI - X2 for the experimental group was $36.66 \pm 9.15$ and for the control group $36.81 \pm 9.82$. We did not find any significant difference in levels of general trait anxiety between groups at the significance level $\mathrm{p}<0,05$. The mean result from the STAI $-\mathrm{X} 1$ at the end of the second day for the experimental group was $34.83 \pm 8.3$ and for the control group $40.87 \pm 11.59$. We did not find any statistically significant difference between groups $(p=0.08)$. Based on calculating the Cohen $d$ we found a moderate effect size between the groups $(d=0.59)$. The mean result from the STAI - X1 at the end of the fourth day for the experimental group was $38.05 \pm 13.03$ and for the control group 37. $37 \pm 9.54$. We did not find either statistical significance nor an effect size between the groups $(p=0,86 ; d=0,05)$. 


\section{DISCUSSION}

The results from the STAI - X2 were very similar between both groups. We can say that there was no difference between the general trait anxiety levels of each group. The results from the STAI - X1 at the end of the second day of skiing were different between groups. Even though we did not find any statistically significant difference, we found a medium effect size $(d=0.59)$. Based on this result we can say that the experimental group had a lower level of state anxiety after two days of skiing on short skis. The results from the STAI - X1 at the end of the fourth day of skiing were similar between groups. We did not find either statistical significance or an effect size between the groups ( $p=0.86 ; \mathrm{d}=0.05)$, although we can see the difference between the second and the fourth day of skiing. The results from the STAI - X1 in the experimental group were $34.83 \pm 8.3$ at the end of the second day and $38.05 \pm 13.03$ at the end of the fourth day. Here we can see a small increase in the state anxiety. This might be due to only having one day for the transition on to standard length skis. The results from the STAI - X1 in the control group were $40.87 \pm 11.59$ at the end of the second day and $37.37 \pm 9.54$ at the end of the fourth day. Here we can see a small decrease in the state anxiety. The control group had a higher score after the first two days of skiing but as they used the same skis for the entire course they might have got used to them and consequentially reduced their level of anxiety.

\section{CONCLUSION}

In our presented paper, the main intention was to determine the effect of different ski length on state anxiety level in novice skiers. Previous studies have shown the importance of the snowplough turn in the teaching process of alpine skiing (Cigrovski et al., 2010; Joksimović et al. 2012) and also the possible effect of short skis on the level of anxiety in novice skiers (Künzell, S. \& Müler, J.,2008; Koca, 2015). Based on the results presented in this paper we can say that teaching alpine skiing with the usage of short skis might be less stressful for novice skiers than with the usage of standard length skis. The crucial part is the transition between short and standard skis. Even though the experimental group had a lower level of state anxiety after two days of skiing, after the transition to standard skis with only one day of training before the final demonstration of four alpine skiing elements, their level of state anxiety increased. On the other hand, the control group, which showed higher levels of state anxiety among its participants after two days of skiing, slightly improved during the rest of the course and after four days of skiing had a lower level of state anxiety than the experimental group.

Unfortunately, the research was limited by time. Each course had only five days. The usage of short skis seems to be helpful to novice skiers but only one day to transition to standard skis is not enough. There are few alternatives for future study. The experimental group could use short skis for only two days and another two days would be used for transition to standard skis. Another alternative is to use short skis for the entire time including the final demonstration of the ski elements. But the idea of using short skis as a tool to improve rather than proper skiing equipment seems to have no use. Ideally, the skiing course would have more than just five days. We could also include more participants for more valid data.

In this paper, we have presented only the data from the measurement of the state anxiety during the process of teaching novice skiers alpine skiing. The whole research was also focused on the efficiency of using short skis and how they affect learning new alpine skiing skills. 
The conclusion about the usage of short skis can be done after processing the remaining data from the entire research. In the next paper, we will evaluate the efficiency of usage of short skis in terms of learning new ski elements.

\section{References}

Božić, I., Cigrovski, V., Bošnjak, G., Jakovljević, V., \&Tešanović, G. (2017). Contribution of Inline Skating to Learning Basics of Alpine Skiing. / Doprinos Rolanja U Učenju Osnova Alpskog Skijanja. SportLogia, 13(1), 1-8.

Cigrovski, V., Matković, B., \& Matković, B. (2010). Can We Make the Alpine Ski Learning More Efficient by Omitting the SnowPlough Technique? / Da Li Je Efikasniji Način Podučavanja Alpskoga Skijanja Bez Primjene Plužne Skijaške Tehnike? SportLogia, 6(2), 51-58.

Havel, Z., \& Kynštová, H. (2013). A comparison of the performance among female students of the specializations Outdoor Activities and Occupational Therapy in the motor tests at the UJEP. Journal of outdoor activities, 7.

Joksimović, D., Joksimović, A., \& Acimović, D. (2012). Effectiveness of Two Methods in Learning Basic Elements of Ski Technique. Research in Kinesiology, 40(1), 77-81.

Koca, F. (2015). Evaluation of state and trait anxiety levels among students with no prior knowledge of skiing before and after the implementation of a skiing course. The Anthropologist, 20(3), 485-491.

Král, L. (2012). Modern ski tuition with the short - ski method. University Review, 6(1).

Künzell, S., \& Müller, J. (2008). The Use of Bigfoots Reduces State Anxiety in Novice Skiers. Journal of Applied Sport Psychology, $20(2), 253-260$.

Lawler, K. (1996). An excerpt from the direct parallel ski instructor manual. Parallel skiing technical report, 003,1

Mical, T., \& Nohejl, J. (2017). Snowsport manual - Modrá kniha lyžování. Špindlerův Mlýn: Asociace profesionálních učitelů lyžování a lyžařských škol, o.s.

Roman, B., Miranda, M.T., Martinez M. Jesus, V. (2007), Transfer from In-line skating to alpine skiing instruction in physical education. In: Muller, E., Lindinger, S. and Stoggl, T. (Ed.), Skiing and Science (pp. 430-439). Oxford, UK: Mayer \& Mayer Sport.

Takahashi, M., Yoneyama, T. (2001). Basic ski theory and acceleration during ski turn. In: E. Müller, H. Schwameder, C. Raschner, S. Lindinger, E. Kornexl (Ed.), Science and skiing, (pp. 307-321). Hamburg: Verlag Dr Kovač.

Vobr, R., \& Heřmánek, R. (2018). The possibilities of coordination assumptions testing of ice hockey players using lowa brace test and mabc-2. Studia Kinanthropologica, 291. 